\title{
Manchas extrínsecas negras - relato de caso clínico
}

\author{
Black extrinsic stain - case report \\ AlessandRa LOUREIRO DE MOURA \\ Graduada em Odontologia pela Pontifícia Universidade Católica de Minas Gerais \\ Marcela de Paula MACEDO \\ Graduada em Odontologia pela Pontifícia Universidade Católica de Minas Gerais \\ Sérgio Milton Martins de Oliveira PENIDO \\ Doutor em Ortodontia pela FOAR-UNESP, Coordenador dos cursos \\ de Aperfeiçoamento e Especialização em Ortodontia da EAP-ABO MG, \\ Depto de Ortodontia, Regional Divinópolis. \\ Cláudia Valéria de Sousa Resende PENIDO \\ Professora Adjunto IV da Pontifícia Universidade Católica de Minas Gerais
}

\begin{abstract}
RESUMO
A descoloração dentária pode ser causada por fatores extrínsecos. Tanto a dentição decídua quanto a permanente podem ser afetadas. O mecanismo de descoloração extrínseco difere de acordo com o agente etiológico. A mancha extrínseca negra é causada por diversos fatores, incluindo bactérias cromogênicas, ingestão de alimentos pigmentados, agentes terapêuticos ou compostos metálicos. A mancha tem, em sua estrutura, composto férrico insolúvel e alto teor de cálcio e fosfato. Ela pode ser removida por meio da raspagem ou polimento coronário realizado pelo profissional. Assim, o objetivo deste trabalho é relatar o caso clínico de um paciente com manchas negras extrínsecas, acompanhado por um período de 14 anos. No caso relatado, o paciente apresentou estas manchas na dentição decídua que, paulatinamente, foram diminuindo, até seu completo desaparecimento na dentição permanente. O tratamento foi relativamente simples e eficaz, fazendo parte do plano de manutenção preventiva.
\end{abstract}

Palavras-chave: DESCOLORAÇÃo DE DENTE; DENTIÇÃO PRIMÁRIA; CÁRIE DENTÁRIA.

\begin{abstract}
Tooth discoloration could be caused by extrinsic factors. It can affect both permanent and primary dentitions. The mechanism of extrinsic discoloration differs according to the etiologic agent. The black extrinsic stain is caused by a variety of things, including chromogenic bacteria, foods, oral therapeutic agents or metal compounds. This stain has an insoluble ferric compound in its structure and high content of calcium and phosphate. It can be removed by scaling and professional polishing. The aim of this study is to report the clinical case of a patient with black extrinsic stain followed-up by 14 years. In this case, the patient had these stains in the primary dentition that were gradually decreasing. In the permanent dentition they disappeared. The treatment was relatively simple and effective as part of the preventive maintenance plan.

Keywords: TOOTH DISCOLORATION; PRIMARY DENTITION; DENTAL CARIES.
\end{abstract}




\section{INTRODUÇÃo}

A alteração da cor dentária em virtude da descoloração ou manchamento é uma condição clínica frequentemente encontrada no consultório odontológico. Pode ser observada tanto na dentadura decídua quanto na permanente e está associada a fatores clínicos e estéticos. As manchas dentárias apresentam características clínicas variadas, pois se diferenciam na etiologia, composição, localização, gravidade e firmeza na adesão à superfície do esmalte dentário. ${ }^{1}$ Existem basicamente dois tipos de descoloração dentária: intrínseca e extrínseca. A primeira é causada por fatores congênitos, sistêmicos ou influência genética. Por outro lado, a extrínseca está condicionada à presença de bactérias cromogênicas no biofilme dentário, ingestão de alimentos pigmentados, utilização de agentes terapêuticos orais e compostos metálicos. ${ }^{2}$

A descoloração por fator extrínseco é a alteração de cor presente no esmalte dentário, mais precisamente na película adquirida. ${ }^{3}$ Este tipo de mancha pode ser causado pela introdução de materiais cromogênicos na cavidade bucal, como alimentos e bebidas; pela utilização de antissépticos bucais, como a clorexidina e sais metálicos polivalentes de estanho e ferro, ou pelo uso de tabaco. O mecanismo de formação, coloração, composição e aderência das manchas é diferente, dependendo do fator etiológico de cada tipo de descoloração. ${ }^{4}$

Manchas extrínsecas, observadas nas dentaduras decídua ou mista, variam nas tonalidades do preto, marrom, verde e laranja. Bactérias cromogênicas estão envolvidas no mecanismo de desenvolvimento deste tipo de descoloração. As manchas de cor verde e laranja estão associadas à má higiene oral, enquanto as de coloração preta e marrom são observadas em crianças com baixa experiência de cárie e boa higienização. ${ }^{4-6}$

A mancha extrínseca negra difere das demais por ser um tipo especial de pigmentação, pois apresenta, em sua estrutura, um composto férrico insolúvel e alto teor de cálcio e fosfato, que modificam a película adquirida. Diversos estudos sugeriram que a produção do pigmento negro tem como principal fator etiológico bactérias cromogênicas, como Actinomyces e Prevotella melaninogênica. ${ }^{7-9}$ O sulfeto férrico é, provavelmente, obtido pela interação entre o sulfeto de hidrogênio, produzido pela ação bacteriana, e o ferro presente na saliva ou no exsudato gengival. ${ }^{7}$ A mancha negra geralmente aparece como uma linha fina, contínua, na região cervical dos dentes ou com coalescência incompleta de pontos seguindo o contorno da margem gengival. Pode ser encontrada nas faces vestibular, lingual ou palatina, particularmente dos dentes posteriores. ${ }^{7}$

O tratamento caseiro não é eficaz para remoção das manchas extrínsecas negras, pois o pigmento encontra-se firmemente aderido à película adquirida. Sendo assim, o uso de escova dentária e dentifrício não é eficaz. A intervenção profissional faz-se necessária por meio de profilaxia com raspagem e polimento coronário, utilizando substâncias abrasivas como pastas profiláticas, ou o uso do jato de bicarbonato de sódio. ${ }^{8,11}$

\section{Proposição}

O objetivo deste trabalho é apresentar o caso clínico de um paciente com mancha extrínseca negra acompanhado pelo período de 14 anos.

\section{ReLATO de CASO CLÍNICO}

Paciente de 1 ano e 7 meses de idade compareceu ao consultório odontológico para tratamento. Sua mãe queixou-se de aparecimento de manchas negras em vários dentes. A história médica não demonstrava alterações sistêmicas ou deficiências de qualquer natureza.

Ao exame extrabucal não foram observas alterações. Ao exame intrabucal foi possível 
perceber pigmentação negra na região cervical das faces vestibular, palatina, lingual e área proximal dos dentes, acompanhando o contorno da margem gengival (Fig. 1). Não foi detectada presença de cárie dentária e a higiene bucal estava satisfatória. $O$ tecido gengival e a mucosa alveolar apresentavam-se normais, sem presença de inflamação.

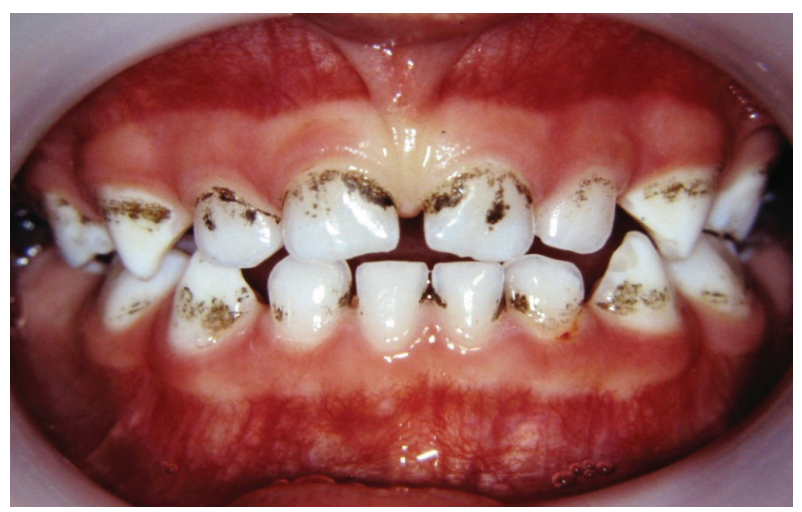

Figura 1 - PRESENÇA dE PIGMENTAÇÃo NEGRA NO TERÇO CERVICAL, FACES VESTIBULAR E PROXIMAL, DOS DENTES DECÍDUOS

Os responsáveis foram informados a respeito do tratamento e da possibilidade de publicação dos dados e, então, assinaram o Termo de Consentimento Livre e Esclarecido (TCLE).

Com base nas características clínicas e na informação de que o paciente não estava utilizando nenhum suplemento à base de ferro, o diagnóstico final foi de mancha extrínseca negra. O tratamento proposto para este tipo de descoloração dentária foi o polimento coronário com escova de Robinson (Microdont $\AA$, Socorro, SP, Brasil) e pasta de pedra-pomes de granulação fina (SSWhite ${ }^{\circledR}$, Rio de Janeiro,
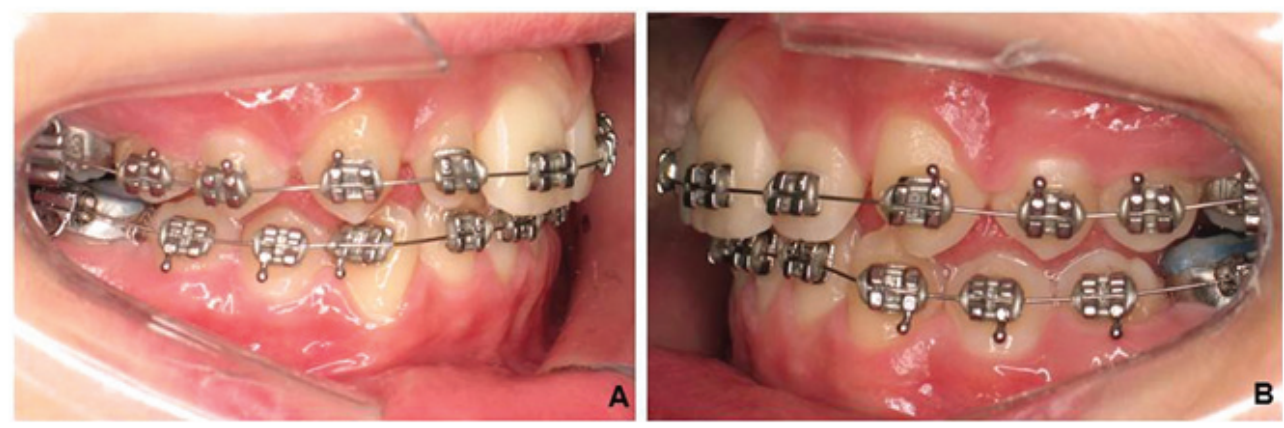

Figura 3 - A e B - DENTES PERMANENTES SEM MANCHAS NEGRAS DURANTE O TRATAMENTO ORTODÔNTICO.
RJ, Brasil) com água.

Após o procedimento, os dentes apresentaram-se limpos, com lisura superficial normal e ausência das manchas.

Foi realizado acompanhamento periódico do paciente ao longo dos anos, de acordo com as consultas de manutenção preventiva. A cada retorno o paciente apresentava novamente manchamento dentário enegrecido, sendo necessária sessão de polimento coronário com pasta contendo pedra-pomes. O tratamento de recidiva das manchas negras foi mantido enquanto $o$ paciente encontrava-se nas dentaduras decídua e mista (Figura 2), até finalizar a irrupção dos dentes permanentes.

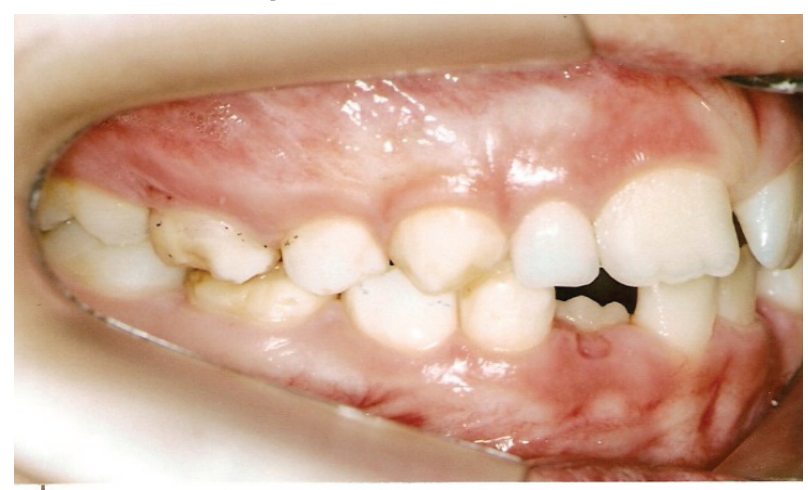

FIGURA 2 - RECIDIVA DAS MANCHAS NEGRAS NA DENTIÇÃO MISTA TERÇO CERVICAL DOS MOLARES DECÍDUOS SUPERIORES.

Posteriormente, o paciente foi submetido a tratamento ortodôntico e, durante esta fase, as manchas não apareceram novamente (Figura 3, A e B). Atualmente, aos quinze anos de idade, o tratamento ortodôntico já foi finalizado. Não houve recidiva das manchas (Figuras 4, A, B e C). 

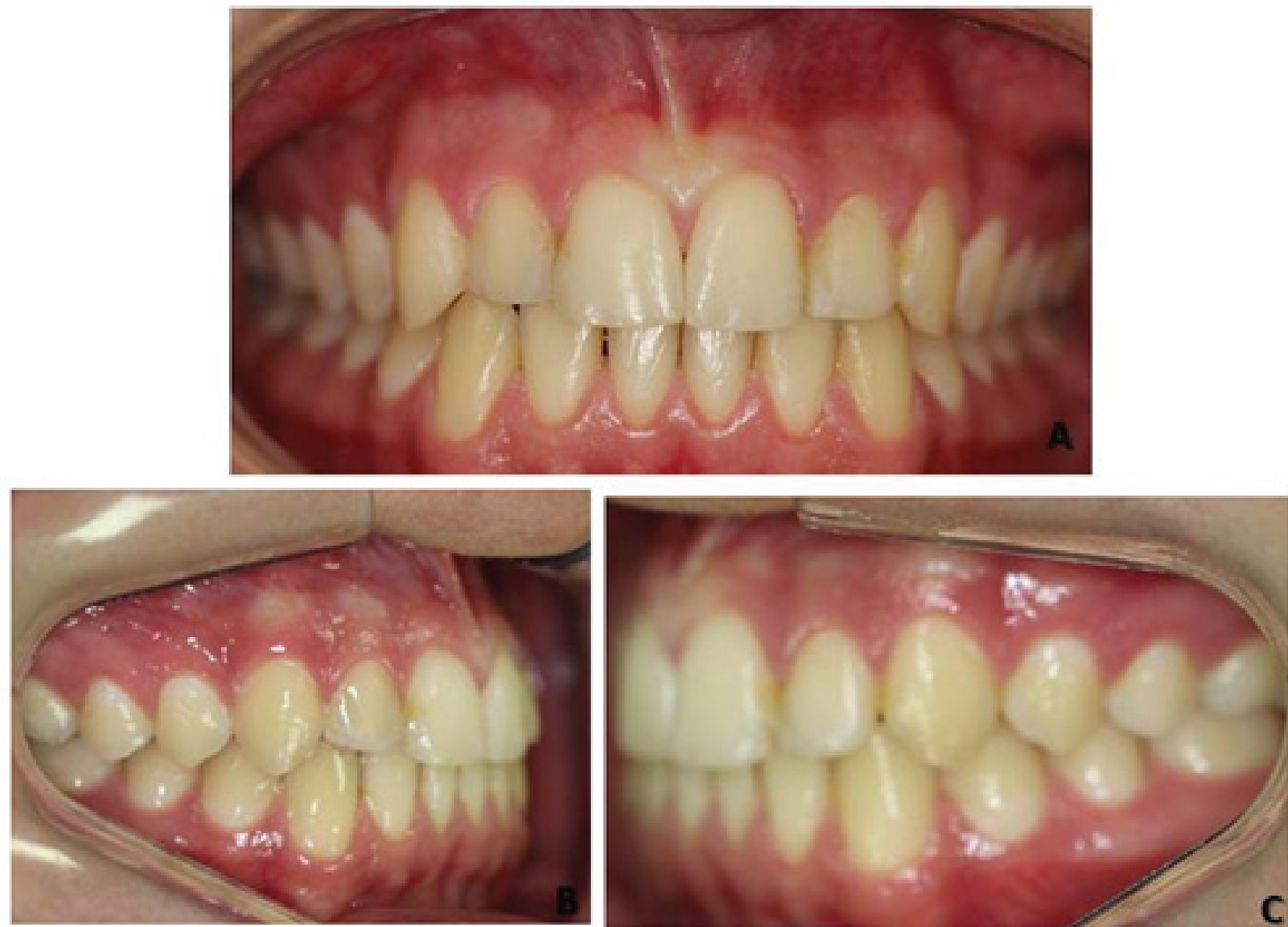

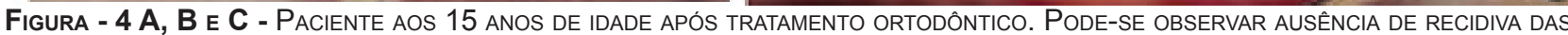
MANCHAS NEGRAS.

\section{Dıscussão}

Manchas intrínsecas são aquelas relacionadas a alterações estruturais do dente e que não podem ser removidas sem que haja alterações dessa estrutura. ${ }^{12,13}$ Por outro lado, as manchas extrínsecas são formadas, essencialmente, por resíduos alimentares, substâncias medicamentosas e bactérias, constituindo depósitos que aderem à superfície do esmalte. A correta análise do tipo de manchamento é fundamental para que $\mathrm{o}$ tratamento seja bem-sucedido. $O$ paciente em questão apresentava manchas dentárias enegrecidas. A literatura sugere que as manchas extrínsecas estão condicionadas à presença de bactérias cromogênicas no biofilme dentário, ingestão de alimentos pigmentados, utilização de agentes terapêuticos orais e compostos metálicos. ${ }^{2}$ Medicamentos contendo ferro também podem ser responsáveis por essa coloração. ${ }^{11}$ No caso clínico relatado, o paciente não estava fazendo uso de suplemento à base de ferro que pudesse justificar a condição apresentada. Este fato foi relevante para o diagnóstico diferencial, comparando-as com outros tipos de manchas dentárias.

A microbiota da mancha negra difere da do biofilme dentário comum por seu aspecto ultraestrutural. Sua microbiota relativamente estável tem predominância de $90 \%$ de bastonetes gram-positivos, os Actinomyces. ${ }^{14}$ A Prevotella melaninogenica, apesar de gramnegativa, e de ser encontrada em pequena porcentagem (1\%), também é citada como um dos principais agentes causais deste tipo de 
mancha. ${ }^{7}$ Neste caso, não houve necessidade de realizar exame microbiológico porque os sinais clínicos foram suficientes para estabelecer o diagnóstico final.

Muitos estudos $7,9,12,13$ demonstraram correlação significativa entre a baixa prevalência de cárie dentária em crianças portadoras de manchas negras. Da mesma forma, foi demonstrado que, quanto mais áreas afetadas pelas manchas negras, menor probabilidade de desenvolvimento da doença cárie, como observado no caso relatado. ${ }^{8}$ Isto pode ser explicado pela tendência de mineralização da mancha negra. Assim como no cálculo dentário, esta mineralização implica pH mais estável pelo alto nível de cálcio e fosfato. Consequentemente, ocorre aumento na capacidade tampão e a dissolução do esmalte dental é reduzida.

De acordo com os estudos ${ }^{7-9,12}$ este tipo de mancha ocorre com maior frequência na dentadura decídua. É comum, após sua remoção, a ocorrência de recidiva nesta fase e na dentadura mista. No caso clínico relatado foi possível confirmar este dado. O paciente apresentou recidiva das manchas enquanto estava nas dentaduras decídua e mista. Já na dentadura permanente, mesmo com o uso de aparelho ortodôntico, que é fator retentivo para o biofilme, não foi detectada a presença de manchas. Os microrganismos envolvidos no desenvolvimento da mancha extrínseca negra fazem parte da microbiota indígena que coloniza a cavidade bucal. Estes coexistem de forma harmônica com seus hospedeiros, porém podem emergir como patógenos oportunistas, estando envolvidos em infecções de tecidos moles e dentes. ${ }^{14}$ Esta pode ser uma das possíveis explicações para o desenvolvimento das manchas negras em crianças, podendo apresentar-se em determinadas fases da vida e em outras, não.

É consenso na literatura que é necessário remover este tipo de mancha por se tratar de depósito pigmentado irritante da gengiva marginal, bem como por comprometer a estética dentária do paciente. ${ }^{12}$ No caso apresentado neste trabalho, o paciente não apresentou alterações do tecido periodontal, mas o prejuízo estético era notável. A profilaxia com escova de Robinson e pedra-pomes e água foi a opção de tratamento. Alguns casos exigem raspagem dentária adicional à profilaxia com pastas abrasivas.

Mais estudos devem ser feitos a respeito da etiologia das manchas extrínsecas. Da mesma forma, seriam interessantes pesquisas longitudinais com o objetivo de observar se há realmente esta tendência de diminuição das manchas ao longo da vida do paciente e a baixa prevalência de cárie. ${ }^{1,8}$ A correta anamnese e adequado exame clínico devem ser sempre realizados a fim de chegar ao correto diagnóstico, pois esta é uma anormalidade que ainda é desconhecida por muitos profissionais da área.

É de suma importância que o clínico geral saiba diferenciar as manchas dentárias extrínsecas e intrínsecas. Para isso, pois, esta anormalidade ainda é desconhecida por muitos profissionais.

\section{Conclusão}

No caso relatado, o paciente apresentou manchas extrínsecas negras na dentadura decídua que, paulatinamente, foram diminuindo até seu completo desaparecimento na dentadura permanente. O tratamento proposto foi eficaz, fazendo parte do plano de manutenção preventiva.

\section{REFERÊNCIAS BIBLIOGRÁFICAS}

1. Hattab FN, Qudeimat MA, Al-Rimawi HS. Dental discoloration: an overview. J Esthet Dent. 1999; 11(6): 291-310.

2. Nathoo SA. The chemistry and mechanisms of extrinsic and intrinsic discoloration. J Am Dent Assoc. 1997; 128(4): 6-10. 
3. Nathoo SA, Gaffar A. Studies on dental stains induced by antibacterial agents and rational approaches for bleaching dental stains. Adv Dent Res. 1995; 9(4): 62-70.

4. Addy M, Moran J. Mechanisms of stain formation on teeth, in particular associated with metal ions and antiseptics. Adv Dent Res. 1995; 9(4): 450-6.

5. Garan A, Akyuz S, Ozturk LK, Yarat A. Salivary parameters and caries indices in children with black tooth stains. J Clin Pediatric Dent. 2012; 36(3): 285-8.

6. França-Pinto CC, Cenci MS, Correa MB, Romano AR, Peres MA, Peres KG, et al. Association between black stains and dental caries in primary teeth: findings from a Brazilian population-based birth cohort. Caries Res. 2012; 46(2): 170-6.

7. Reid JS, Beeley JA, MacDonald DG. Investigations into black extrinsic tooth stain. J Dent Res. 1977; 56(8): 895-99.

8. Gasparetto A, Conrado CA, Maciel SM, Miyamoto EY, Chicarelli M, Zanata RL. Prevalence of black tooth stains and dental caries in Brazilian schoolchildren. Braz Dent J. 2003; 14(3): 157-61.

9. Mayta-Tovalino FR, Torres-Quevedo JC. Pigmentaciones negras extrínsecas y su asociación con caries dental en niños con dentición mixta. Rev Estomatol Hered. 2008; 18(1): 16-20.

10. Eriksen HM, Solheim H, Nordbo H. Chemical plaque control and prevention of extrinsic tooth discoloration in vivo. Acta Odontol Scand. 1983; 41(2): 87-91.

11. Igreja G, Miotto MHMB, Baptista G. Estudo de fatores responsáveis por manchas dentárias extrínsecas. Rev Odont Univ Fed Esp Santo. 1999; 1(2): 36-4.

12. Costa SC, Imparato JCP, Franco AEA, Camargo MCF. Estudo da ocorrência de manchas extrínsecas negras em crianças e sua relação ao baixo índice de cárie dental. Rev Odontol Univ St Amaro. 1997; 2(4): 36-8.

13. Caldas CT, Mialhe FL, Silva RP. Prevalência de manchas dentais extrínsecas negras e sua relação com a cárie dentária em crianças do município de Santa Terezinha de Itaipu - PR. RFO UPF. 2008; 13(2): 22-6.

14. Bandon D, Chabane-Lemboub A, Le Gall M. Exogenous tooth discoloration in children: black stains. Arch Pediatr. 2011; 18(12): 1348-52.

Submetido em: 20-11-2012

Aceito em: 2-4-2013 